\title{
Current Approaches to the Concept of Occlusion in Implantology
}

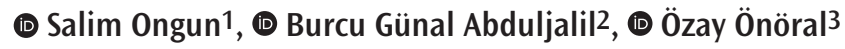 \\ 1Department of Prosthetic Dentistry, Near East University, Faculty of Dentistry, Nicosia, Cyprus \\ 2Department of Prosthetic Dentistry, Near East University, Faculty of Dentistry, Nicosia, Cyprus \\ ${ }^{3}$ Department of Prosthetic Dentistry, Near East University, Faculty of Dentistry, Nicosia, Cyprus
}

\section{Abstract}

Successful dental implant applications can be achieved with an appropriate indication, correctly applied surgical intervention, careful prosthetic planning, and high oral hygiene. As is known, occlusion is a very important and critical factor. The implant bone interface is not a structure that can resist the incoming forces, such as natural teeth, thus more care should be taken in the arrangement of occlusion in implant-supported prostheses. Studies showed that occlusion applied in implant-supported prostheses is the most important factor that affects long-term success. However, scientific data regarding occlusion and implementation principles are still insufficient. Therefore, this study aimed to determine the types of occlusion that are used in implant-supported prostheses following the edentulous cases and increase awareness regarding the occlusion in implant-supported prostheses.

Keywords: Implant; prosthetic restoration; occlusion; all-on-4

\section{INTRODUCTION}

Implant-supported fixed prostheses have recently become a desired treatment option in the rehabilitation of patients with lacking teeth due to their success rates. ${ }^{1}$ Occlusion plays a functional and biologically important role in the success and longevity of prosthetic restorations. ${ }^{1-3}$ The concept of occlusion in implant-supported prostheses has been proposed based on natural dentition and the occlusion concept in full dentures. ${ }^{4}$

In an ideal occlusal relationship, the loads on the teeth should be evenly distributed. Horizontal forces that can affect the teeth should be avoided or at least minimized. Therefore, the loads come parallel to the long axis of the teeth. According to Okeson ${ }^{5}$, the muscular and skeletal stable position of the joints can only be maintained under stable and ideal occlusal conditions that are achieved by equal and simultaneous contacts of all teeth and by directing the occlusal forces parallel to the long axis of the tooth. The following are 3 acceptable occlusal schemes: (1) Balanced occlusion, (1-i) bilaterally balanced occlusion, and (1ii) lingualized occlusion; (2) Group functional occlusion (with unilateral balance); and (3) Mutual protective occlusion, (3-i) Canine guidance, and (3-ii) Anterior group guidance.

\section{Occlusion in Implantology}

For the last 25 years, the implant application in partial or fully edentulous patients has caused changes in the prosthetic treatment options, and prostheses have been placed on the

To cite this article: Ongun S, Günal Abduljalil B, Önöral Ö. Current Approaches to the Concept of Occlusion in Implantology.

Cyprus J Med Sci 2021;6(Suppl 1):75-83

ORCID iDs of the authors: S.0. 0000-0002-4359-8941; B.G.A. 0000-0001-5098-1765; Ö.0̈. 0000-0002-5264-9376. 
implant substructures. The major drawback encountered in implant rehabilitation includes implant loss. Implant loss can be grouped into two large groups. The first is the early losses that occur during the surgical protocol, and the second is the late losses after osseointegration. Late losses after osseointegration may be due to several reasons, including bone resistance, plaque formation, and excessive occlusal loading. ${ }^{6}$ Many pieces of literature say that excessive occlusal loading can cause bone loss around the implant, ${ }^{7-9}$ as well as mechanical complications in implants and prostheses, such as screw fractures, prosthesis, and implant fractures. ${ }^{10}$

Proper prosthetic knowledge and practice are required for good implant therapy. Appropriate occlusion is a critical factor in the long-term use of the implant after a successful implant application. ${ }^{6}$ Regardless of how successful the surgical technique is, the stresses that exceed physiological limits are the main reason for bone resorption around the implant. ${ }^{11}$ One of the important etiological factors in implant loss is trauma due to occlusion. Radiological stratification or groove observation is also associated with excessive occlusal loading. ${ }^{12}$

Natural dentition may show a physiological adaptation to traumatic occlusion. ${ }^{12}$ In the function of the jaws with natural teeth, the implant bone substructure does not have forces against the forces coming to the jaws that carry the implantretained prosthesis, whereas the periodontal ligaments have the opportunity to absorb incoming forces or allow the movement of the tooth at physiological limits. The compressibility and deformability of the periodontal ligament in natural teeth lead to differences in force adaptations compared to implants. ${ }^{13}$ The natural tooth moves quickly between $56-108 \mu \mathrm{m}$ and rotates in the $1 / 3$ apical of the root during lateral loading in force application, thereby reducing the lateral forces in the tooth. Contrarily, the implant gradually moves. Under the same lateral force, implants can reach $10-50 \mu \mathrm{m} .{ }^{14}$

When the implant with an incorrect occlusion is not corrected for occlusion and exposed to excessive occlusal forces, the force will directly affect the implant bone interface. ${ }^{12}$ If the formed occlusal force exceeds the capacity of the absorb tension interface, implantation will fail and the implant will be lost. ${ }^{13}$ The implant site capacity to withstand occlusal forces depends on (i) zone difference (occlusal forces increase backward) and (ii) supporting bone quality (a stable bone without augmentation is a golden standard).

Another issue that increases the importance of occlusion in the implant-retained prosthesis is that while the natural teeth have neuromuscular mechanisms and a proprioceptive mechanism to protect them from the harmful forces upon them, no such specific mechanism for implant-retained prostheses is available.
Therefore, individuals using implant-retained prostheses cannot fully control the forces during functional jaw movements, and it becomes difficult for them to notice any error in occlusion or a point where the force intensifies. ${ }^{15}$ No periodontal ligament is determined in the basic structure of osseointegration, and the proprioceptive potential is less than the tooth. The implant is rigidly-placed, thus much less likely to be embedded or moved. ${ }^{12}$

With a force above physiological limits on the implants, the bone responds with resorption. The most important reason for cervical bone resorption that occurs after implantation is excessive forces due to incorrect occlusal arrangements. In addition to bone resorption, shear forces that may occur because of improper occlusion may cause cement separation in cement-retained prostheses and fracture of screws and other denture fasteners. ${ }^{15}$ However, the structure of occlusal contacts and relationships may change due to the tooth or prosthesis, loss of tooth or implant, and mucous atrophy. Therefore, the occlusal relationships of implant-supported prostheses should be regularly checked (at short intervals of 3-6 months). ${ }^{12}$

\section{Causes that Overloads Implants}

Excessively long cantilevers ( $>15 \mathrm{~mm}$ in the lower jaw and $12 \mathrm{~mm}$ in the upper jaw): Long cantilevers applied to implant prostheses may cause overload in implants, peri-implant bone loss, and prosthetic failures. ${ }^{16}$ When bite force is applied to the prosthesis with the distal wing, the highest axial and tipping forces are observed in distal implants. This situation was higher in those supported with three implants compared to prostheses supported with five or six implants. ${ }^{16}$ In cases where the cantilever length is $>15 \mathrm{~mm}$, more implant prosthesis failure is observed than in cases of $<15 \mathrm{~mm} .{ }^{17}$

Para-functional movements: Para-functional movements and improper occlusal design were reported to be related to implant bone loss, implant fall, implant fracture, and prosthesis failures. ${ }^{18}$

Excessive premature contacts: Excessive premature contacts have been reported to cause loss of osseointegration and excessive marginal bone loss in premature contacts at $100 \mu \mathrm{m}$ height. $^{18}$

Wide occlusal plate: Generally, narrowing the occlusal plate by $30 \%-40 \%$ in the molar region is recommended. The narrowed occlusal tray will reduce the forces and the tipping moment that will come out of the long axis of the implant. ${ }^{19}$

Increased tubercular slopes: Studies reported that tubercular slopes are one of the most important factors in tipping moment formation. The flatness of the area around the centric contacts will transmit the occlusal forces in the apical direction. ${ }^{19}$ 
Low bone density and quality: Low-density bone will be more susceptible to occlusal forces and this will prolong the recovery time. $^{6}$

The insufficient number of implants: Proper sharing of force between implants will increase the success rate. ${ }^{6}$

\section{Ideal Occlusion in Implant-Supported Prostheses}

The first study on which occlusion type is more appropriate in implant prosthesis was done by Leihom in $1983,{ }^{15}$ wherein Leihom suggested bilaterally balanced occlusion due to bone resorption in cases where the forces are not evenly distributed. ${ }^{15}$ However, bilaterally balanced occlusion type has been reported to create an extremely destructive effect on the implantsupported fixed prosthesis of individuals whose bone in the posterior region is much weaker compared to other regions due to the principle of evenly distributed forces. ${ }^{6}$

In 1986, Jemt stated that occlusion should be in full contact in all tooth groups and tubercle-fossa relationship in maximum intercuspal position in implant-supported prostheses, and the lateral loads should be distributed in the anterior region in all eccentric movements and create a disclusion occlusion in the posterior segment. ${ }^{6}$ This view is especially valid in full mouth fixed restorations where the lateral and posterior segments are extremely sensitive to lateral forces. ${ }^{20}$ Therefore, the meaning of ideal occlusion in implant-supported restorations is not different from the meaning in natural dentition.

Geometry, number, length, diameter, angulation, and location of implants, type, and geometry of prosthesis, prosthetic material, fit of the superstructure, direction and severity of prosthetic loads, opposing arch status, mandible deformation, bone density, patient age, and gender can influence occlusion. Thus, determining the ideal occlusion type for implant-on-implant prostheses following a single factor is misleading. Therefore, each case should be evaluated within itself, and the appropriate occlusion type should be determined by considering all the above-mentioned factors. ${ }^{21}$ Mericke-Stern et al. ${ }^{22}$ listed the basic principles of occlusion in prosthesis as follows:

- Bilateral stabilization should be provided in centric occlusion.

- Occlusal contacts and forces should be equally distributed.

- There should be no conflict between the centric occlusion in the back position.

- There should be wide freedom in centric occlusion.

- Anterior guidance should be provided.

- The working and balancing sides should have lateral wandering movements without conflicts.

\section{Occlusion in Implant-Supported Prostheses Applied Without a Single-Tooth}

The most important point in single dental implants is to make prosthetic restorations that do not allow rotation. Additionally, in these restorations, the tooth form with less tubercle height inclination should be modeled and full protection should be provided in lateral and protrusive movements. ${ }^{11}$

The success rate of single dental implants prepared in the posterior region is relatively lower than implants that are placed in the anterior region because the height of the bone where the implant will be placed in this region is low due to restrictive anatomical factors, such as maxillary sinus and mandibular nerve. In this region, bone quantity is generally minimal and occlusal forces are higher. ${ }^{23}$

The largest implant that can be placed should be preferred to eliminate offset contacts. Complications such as screw and implant fracture and screw loosening can be seen due to occlusal forces. A three-point contact (tripodal centric occlusal contacts) should be provided in single-tooth restorations, the occlusal plate should be narrowed, and the occlusal plate should be shaped to direct the forces to the long axis of the implant to eliminate these complications and at least reduce their damage. ${ }^{24}$

In centric occlusion, the implant-supported crown should have a gap of $30 \mu \mathrm{m} .{ }^{25}$ This distance is particularly important as the implant-supported prostheses cannot move while natural teeth can move in their periodontal sockets under heavy loads. If this occlusal space is not sufficiently provided, implant-supported prostheses are exposed to heavy loads. Additionally, patients cannot understand whether their implant-supported crowns are high because no periodontal membrane is found around their implant, with a limited proprioceptive mechanism. Faint contacts should be provided in the eccentric relationship to eliminate lateral forces. The implant is protected from excessive mechanical loads if the implant can be concealed within the natural occlusion using infra-occlusion. ${ }^{25}$

The patient's current occlusion will be used in single-tooth restorations. However, a single implant placed in the canine area will be under a great load while providing the disclusion of the teeth in the mouth. Group function occlusion should be preferred in these patients to distribute the incoming occlusal forces to the anterior and posterior teeth.

In restorations made, occlusion should be rechecked before and after cementation with 40-micron thick articulating paper. Bilateral and simultaneous occlusal contacts should be provided, and early contact points should be eliminated. ${ }^{26}$

In single dental implants, the occlusal forces on the implant should be minimized, whereas the force transmission to the adjacent teeth should be maximized. ${ }^{6}$ 
Anterior and lateral guidance should be provided on the natural tooth. Working and balancing side contacts on single-tooth restoration should be prevented. ${ }^{6}$ Mild or moderate non-contact, hard light contact is a reasonable approach to distribute occlusal forces between the implant and the teeth in the maximum intercuspal position. ${ }^{27}$

Reducing the inclination of the tubercle is necessary for posterior single dental implants to create contact areas with a 1-1.5 $\mathrm{mm}$ flat surface oriented to the center and apply a narrowed occlusal table. ${ }^{28}$ Wennerberg and Jemt ${ }^{29}$ stated that in single molar implants, occlusal contact located in the center reduces bending moments, as well as mechanical problems, and implant fractures.

\section{Occlusion in Implant-Supported Prostheses Applied in the Partially Edentulous Cases}

The restoration of edentulous crests with distal extensions has been a controversial issue. There are two types of treatment approaches in Kennedy class I and II cases: 1) Planning an implant-supported prosthesis separately made from the natural dentition by placing two implants on the crest in the distal extension area, which can be screw-retained or cementretained, and 2) dental implant supported fixed prosthesis planning using natural teeth adjacent to the toothless area with a distal implant. ${ }^{11}$

Canine preservative occlusion should be used with anterior teeth in the application of fixed bridges for the posterior region on the implant, implant supports in Class I or II partial edentulous cases. Thus, the forces that can come to both the alveolar bone and the support are ensured to reduce and relieve the stresses..$^{30}$

Natural physiological dentitions often have canine preservative and group function occlusion. If these are not damaged by tooth extraction, they should not be randomly damaged with prosthetic applications. With anterior teeth, occlusion with canine guidance should be used. Thus, in lateral and forward movements of the lower jaw, the posterior teeth are separated from each other under the guidance of the canine and lose their contact. ${ }^{23}$

If the patient has lost canine teeth or has periodontal damage, group function is preferred. Thus, the incoming forces are distributed between the teeth and implants without concentrating on the implant. With small molars in the mouth, group function is also preferred. ${ }^{11}$

In Kennedy's class III cases, the distance between the implants and the occlusal surfaces of opposing teeth should be $30 \mu \mathrm{m}$ during light or medium contact of natural teeth located in the anterior or posterior toothless area, as in single-tooth implants. Loading should be as axial as possible and contact should be avoided during protrusive and lateral movements. ${ }^{27}$ In Class III and IV partial edentulism cases, group functional occlusion or canine guidance occlusion type should be used. ${ }^{31}$

In the group function, all buccal tubercles of the working teeth side are in contact, whereas no contact should be made with any teeth on the balance side. The group function closure type is used to distribute the incoming loads to all implant supports without concentrating on a single implant and prevent excessive lateral forces on the implant. ${ }^{11}$

Group function or unilateral balanced occlusion establishment is necessary in cases where canines are extracted or periodontally damaged. Fully adjustable articulators should be used to ensure occlusion. ${ }^{30}$

In Kennedy class IV cases, in maximum intercuspal position, contact with the anterior teeth should be avoided and loads should be covered by the posterior natural teeth. If an implant is located in the canine area, the clinician has to decide whether to include this implant in lateral movements. ${ }^{27}$

The following factors should be considered in Class IV Anterior restorations: ${ }^{30}$

- If fixed restorations are to be made, no contact should be created between the teeth in the anterior region.

- In patients with anterior removable restoration, the anterior artificial teeth should not have contact or should be passive, occlusal contact should be in protrusive or lateral movements.

- If a flat (monoplane) occlusion is chosen, anterior tooth contacts should be preferred during the function.

- The distal tipping moment at the anterior bridges should not exceed the anteroposterior length of the implant.

\section{Occlusion in Implant-Supported Prostheses Applied in the Fully Edentulous Cases}

\section{Occlusion in Implant-Supported Overdenture Prostheses}

Balancing the forces is extremely important in both jaws. If the opposite jaw is toothless, an implant-supported fixed prosthesis should not be the first choice. A mandibular overdentures supported by two implants would be more appropriate for planning when using a flexible attachment that provides mobility. The occlusal loads are equally distributed to two implants by placing the implant in the canine areas in the anterior region and connecting these implants with a bar. In mucosa-implantsupported prostheses, 4 implants are placed in the anterior region of the mandible and combined with a bar. ${ }^{31}$

With sensitive and easily irritated mucosa, alveolar nerve pressure due to mandibular bone resorption, a gag reflex, and a knife-ridge crest or sharp mylohyoid edge, only implant- 
supported overdentures should be preferred. The support of 4-6 implants between the mental foramina is used. Function in the posterior region is provided by the bilateral extensions of the prosthesis. If the opposite arch contains natural teeth, this type of overdenture prosthesis is preferred to ensure correct stress distribution. ${ }^{31}$

Under normal conditions in overdentures, bilaterally balanced lingualized occlusion is recommended in a patient with a normal crest. Monoplane occlusion should be used in excessively resorbed crests. ${ }^{22} \mathrm{~A}$ consensus that bilaterally balanced occlusion is advantageous in terms of the stability of overdenture is made; however, not many clinical studies compared it with other occlusions. ${ }^{6}$

Peroz et al. compared balanced occlusion with canine-guided occlusion in 22 patients using traditional complete dentures in their clinical study. Using an analog scale, canine guidance was shown comparable to balanced occlusion in prosthetic retention, aesthetic appearance, and function. ${ }^{6}$ Çalıkkocaoğl $u^{20}$ stated that lingualized occlusion should be used instead of a balanced occlusion in implant-supported overdenture prostheses.

In conclusion, when adjusting occlusion in implant-supported overdenture prostheses applied to a fully edentulous patient, a lingualized or balanced occlusion type should be preferred since the posterior area is supported by the mucosa, whereas the anterior region is supported with prosthetic attachments. Additionally, the tubercles in the teeth used in the removable dentures should be at a slope that will not interfere with horizontal movements. The occlusal plate width should also be narrower than normal prostheses.

\section{Occlusion in Implant-Supported Fixed Full-Arch Prostheses}

Bilateral balanced occlusion is recommended in cases with complete dentures in the opposing arch for full-arch fixed prostheses. Canine-guided occlusion is recommended in cases with the natural tooth in the opposing arch or cases with the upper and lower fixed implant-supported prosthesis. Some studies suggested providing mild anterior guidance in situations opposing to the natural tooth. ${ }^{6}$ Group function occlusion is recommended in cases where the implant cannot be placed in the canine area due to anatomical conditions. ${ }^{12}$ Recently, the literature suggests lingualized occlusion as the ideal occlusion in implant-supported fixed or removable prostheses. ${ }^{12}$

Bilateral and anteroposterior simultaneous contacts are reported to be obtained at the centric relationship and maximum intercuspal position to distribute occlusal forces during navigational movements. ${ }^{6}$ Contact should be removed in lateral movements in the areas where cantilevers are applied. Providing 1-1.5 mm of freedom in the centric relation in occlusal contacts will prevent premature contacts that will occur during function. ${ }^{32}$ Working side contacts that are anteriorly placed are recommended to prevent posterior overload. ${ }^{33}$ If there is a cantilever extension in full-arch fixed restorations, providing a small $(100 \mu \mathrm{m})$ infra-occlusion to the cantilever area will reduce the load on the prosthesis. ${ }^{6}$ Higher success has been reported in prostheses with a cantilever length of $<15 \mathrm{~mm}$ in the lower jaw. Cantilevers $<12 \mathrm{~mm}$ should be applied in force direction and bone quality in the upper jaw. Today, the optimal amount of distal cantilever is recommended as only $7 \mathrm{~mm} .{ }^{12}$

Two occlusal planes are defined and recommended for fullarch implant-supported fixed prostheses: (a) canine-guided occlusion and (b) lingualized occlusion. Only the posterior teeth are in contact with the centric relationship in the canine-guided occlusion concept. The upper palatal tubercles and lower buccal tubercles are closed by the fossa of the opposing teeth. The posterior teeth are in disclusion and the incisal edges guide the lower jaw in the protrusive movement. In lateral movements, it guides along the lingual surface of the upper canine, the distal slope of the lower canine, and the mesial slope of the buccal tubercle of the first premolars. ${ }^{15}$ Thus, the anterior teeth protect the posterior teeth or implants against destructive lateral forces during eccentric movements. This occlusion is defined as the most effective occlusion type in terms of chewing, and at the same time, is highly preferred for optimum aesthetic appearance. ${ }^{12}$ However, the creation, alignment, and regulation of such an occlusion require significant laboratory and technical experience and a good clinical experience. Canine-guided occlusion requires multiple and simultaneous posterior contacts. These contact points should be in the form of a tripodal tubercle-fossa relationship. Lateral forces should be avoided as much as possible. ${ }^{34}$ The creation and arrangement of such complex contacts is a very difficult procedure for full-arch implant-supported prostheses. Chairside occlusal arrangements are usually required.12

Alternative occlusal planes were proposed after it was realized that the preparation and maintenance of the canine-guided occlusion were difficult and time-consuming. Lingualized occlusion is generally recommended for full-arch implantsupported restorations. Their purpose is similar, but the major benefit of this occlusal plane is its ease of application and adaptation. It directly transmits the incoming forces to the long axis of the implants. No contact was made between the lower buccal tubercles and the upper palatal tubercles. Preparation time in the laboratory is reduced and this occlusal plane defines posterior occlusion, which is more easily observed in the laboratory and clinical environment and therefore unwanted occlusal contacts can be identified and corrected more easily. ${ }^{12}$ A minor disadvantage of the lingualized occlusion type is the slight gap between the buccal tubercles of the lower teeth and the upper teeth. This gap does not create aesthetic problems as it occurs in the posterior region of the arch. ${ }^{34}$ Especially in full- 
arch implant-supported fixed restorations, the occlusion should be well evaluated, and the incoming forces should be equally distributed. Therefore, help can be obtained from computeraided occlusal analysis methods (T-scan system). ${ }^{18}$

Both quantitative and qualitative methods are used to evaluate occlusal relationships. Using qualitative methods, only the occlusal contact point localization can be determined. Among the quantitative methods used in the occlusal relationship evaluation, T-scan and photo-occlusion systems are used to align the contacts and determine their density. Especially in full-arch fixed implant-supported restorations, occlusion should be well evaluated and incoming forces should be equally distributed. ${ }^{12}$

The T-scan system consists of a sensor, handle, processing unit, and an installed printer. When the patient correctly bites the sensor, it turns into data on the closing screen. This occlusion analysis method shows the pressure of occlusal contacts and the changes in this pressure within the time until maximum contact occurs, as the patient begins to bite the sensor. ${ }^{3}$ It gives information on the early contacts after the onset of occlusion. Since the occlusion paper marks all contacts, information about which contact occurs first is not provided..$^{12}$ The T-scan occlusal analysis method is used for the following purposes:

- Compensating occlusion during dentin rehearsal of fullarch restorations

- Balancing after trial and finishing of complete dentures

- Balancing the splint in patients with temporomandibular joint problems

- Elimination of early contact of implant-supported prostheses

- Adjusting the pressure on the implants as desired in implant studies

- Balancing occlusion after all orthodontic work

- Determining the location of occlusion-induced pain that cannot be localized by the patient. ${ }^{12}$

\section{Occlusion in Natural Teeth Implant-Supported Fixed Prostheses}

Skalak ${ }^{35}$ and Sullivan ${ }^{36}$ reported that connecting implants to natural dentition is a potential danger for implants and teeth. Various studies ${ }^{37-39}$ suggested the use of non-rigid connections between natural teeth and implants. Additionally, some implant systems have tried to imitate the periodontal membrane using resilient elements between the implant and the superstructure.

If the number, axis, and position of the implant are in doubt, the attachment of the natural tooth to the implant with rigid attachments is thought to provide additional support to the implants. ${ }^{40}$ Gunne et al. ${ }^{41}$ reported that tooth implant-supported prostheses have no negative effects on the success rate and can be recommended as a safe treatment alternative.

The idea of connecting natural teeth with implants has been discussed for a long time. Connecting the implants placed rigidly in the bone and teeth that have certain mobility is less preferred. Providing an ideal occlusion in fixed prostheses that receive support from these two structures that are connected with the bone in completely two different ways is quite difficult. ${ }^{34}$

Distributing the force equally in restorations where implants that can move 10-50 microns in the bone are attached with natural teeth with the elasticity and adaptation capacity of the periodontal ligament is difficult. Occlusion is much more difficult to adjust in tooth implant-supported prosthetic restorations as it is unstable due to minor dentition changes. ${ }^{23}$

A detailed study about the occlusion in this type of prosthesis with one or more implants in the posterior region and natural teeth in the anterior region is unavailable, thus a gap of $30-50 \mu \mathrm{m}$ is recommended between the opposite arc to reduce the moment of force on the implant. The loads from light and moderate contacts are transmitted to the alveolar bone employing natural teeth. The load at higher contact is distributed between the natural tooth, the implant, and the prosthesis. ${ }^{27}$

\section{Occlusion in All-0n-4 Prostheses}

All-on-four treatment concept has been developed to maximize the use of existing bone in atrophic jaws, achieve immediate function, and avoid both regenerative procedures that increase the cost of treatment and disease duration and the complications inherent in these procedures. ${ }^{42}$ The protocol developed by Malo et al. ${ }^{43}$ immediately loaded a temporary fixed prosthesis using four implants in fully edentulous jaws. While the foremost two implants are placed axially, the posterior implants are placed distally at an angle of up to $45^{\circ}$ to minimize the cantilever length and allow the application of prostheses including up to 12 -unit teeth. ${ }^{43,44}$ High survival rates have been observed in implants in this concept. ${ }^{45,46}$ However, some mechanical and biological complications associated with this concept were reported. ${ }^{46-48}$ Occlusal overload is associated with the load after mechanical treatment, thus success becomes difficult when occlusal compliance is not optimized. ${ }^{6,49}$

Kim et al. ${ }^{6}$ conducted a literature review to determine the preferred types of occlusion in implant prostheses. Accordingly, based on the condition of the prosthesis in fixed prostheses on implants, bilateral balanced, group function, or canine-guided occlusion may be preferred. However, Kim et al. ${ }^{6}$ reported that this information was not supported by sufficient evidence. Scientific evidence on the type of occlusion to be preferred in the All-on-Four concept, which is a relatively new treatment concept, 
is limited, and consensus statements have been formulated but remain controversial. ${ }^{50,51}$

Many studies treated interferences in excursive dynamic movements through the establishment of centric and lateral contacts within the inter-canine zone in attempting to secure mutually protected occlusion..$^{52-54}$ Tallarico et al. ${ }^{47}$ used mutually protected occlusion with anterior guidance or balanced occlusion in cases of opposing natural dentition, fixed prosthesis, or complete denture. Ayna et al..$^{55}$ described the use of pressuresensitive film in occlusion control of All-on-Four prostheses using a software application called Appendant.

Türker et al. ${ }^{56}$ used different types of occlusion (bilateral balanced, group function, canine-guided, lingualized, and monoplane occlusion) in acrylic prostheses prepared according to the All-on-Four concept in the maxilla and mandible, and occlusal relation that occurs during chewing. He evaluated the stress distribution on the implants and alveolar bone based on the load using the finite element analysis method. He stated that the lowest stress values on alveolar bone and implants were observed in canine-guided occlusion.

Türker et al. ${ }^{57}$ examined the stress values created by different types of occlusion (group function, canine-guided, and lingualized occlusions) on abutments, screws, and prostheses using the 3-dimensional finite element analysis method in the All-on-Four concept. Within the limits of the study, group function occlusion can be recommended to reduce stress on screws, abutments, and prostheses in the All-on-Four concept.

\section{CONCLUSION}

The prosthesis type and occlusion to be arranged should be determined by considering the patient's current occlusion and biomechanical parameters, such as implant orientation, bone density, and functional surface area dimension. No single special form of occlusion is determined in oral implantology. With a short-span fixed partial prosthesis or a single implant-supported crown constructed, the centric relationship and maximum tubercle contact should be provided, but the tubercles should not interfere in the eccentric position. When conventional prostheses are applied in class I and class II restorations, posterior disclusion should be applied. In class III and class IV restorations, the patient's current occlusion or group function occlusion should be applied, just as in individuals with natural teeth. The occlusion type of prosthesis on multiple implants made in a fully edentulous patient should be preferred as canine-guided in the presence of natural teeth in the opposite jaw, and bilaterally balanced occlusion in the presence of a full prosthesis in the opposite jaw. Çalıkkocaoğlu ${ }^{20}$ stated that lingualized occlusion should be used in overdenture prostheses.

\section{Main Points}

- The establishment of correct occlusion has clinical significance for the long-term success of the implant-supported prosthesis.

- Excessive occlusal loads may cause bone loss, as well as mechanical complications, in implants and prostheses, such as screws, prostheses, and implant fractures.

- No single special form of occlusion is determined in oral implantology. The occlusion type has to be separately selected for each case.

\section{ETHICS}

Peer-review: Externally peer-reviewed.

\section{Authorship Contributions}

Conception: S.O.; Design: S.O.; Supervision: S.O.; Data Collection and/or Processing: B.G.A.; Analysis and/or Interpretation: B.G.A.; Literature Review: Ö.Ö.; Writing: Ö.Ö.; Critical Review: Ö.Ö.

\section{DISCLOSURES}

Financial Disclosure: The author declared that this study had received no financial support.

Conflict of Interest: The authors declared no conflict of interest.

\section{REFERENCES}

1. Yuan JC, Sukotjo C. Occlusion for implant-supported fixed dental prostheses in partially edentulous patients: a literature review and current concepts. J Periodontal Implant Sci. 2013;43:51-57.

2. Goodacre CJ, Bernal G, Rungcharassaeng K, Kan JY. Clinical complications with implants and implant prostheses. J Prosthet Dent. 2003;90:121-132.

3. Chapman RJ. Principles of occlusion for implant prostheses: guidelines for position, timing, and force of occlusal contacts. Quintessence Int. 1989;20:473-480.

4. Sadowsky SJ. The role of complete denture principles in implant prosthodontics. J Calif Dent Assoc. 2003;31:905-909.

5. Okeson JP. Management of Temporomandibular Disorders and Occlusion. 6th ed. St Louis: Elsevier Mosby; 2008.

6. Kim Y, Oh TJ, Misch CE, Wang HL. Occlusal considerations in implant therapy: clinical guidelines with biomechanical rationale. Clin Oral Implants Res. 2005; 16:26-35.

7. Rangert B, Krogh PH, Langer B, Van Roekel N. Bending overload and implant fracture: a retrospective clinical analysis. Int J Oral Maxillofac Implants. 1995; 10:326-334.

8. Isidor F. Histological evaluation of peri-implant bone at implants subjected to occlusal overload or plaque accumulation. Clin Oral Implants Res. 1997;8:1-9.

9. Miyata T, Kobayashi Y, Araki H, Ohto T, Shin K. The influence of controlled occlusal overload on peri-implant tissue. Part 3: A histologic study in monkeys. Int J Oral Maxillofac Implants. 2000;15:425-431. 
10. Schwarz MS. Mechanical complications of dental implants. Clin Oral Implants Res 2000;11(Suppl 1):156-158.

11. Bayındır F, Denizoğlu S. Dental implant Protezleri İçin Okluzyon Tipinin Seçimi. Atatürk Üniv Diş Hek Fak Derg. 1999;9:87-90.

12. Özkan K, Y. Tam Protezler ve Implant üstü Hareketli Protezler. 1st ed. İstanbul: Vestiyer Yayın Grubu; 2011.

13. Misch CE. Contemporary Implant Dentistry. 3rd ed. St Louis: Mosby Elsevier; 2008.

14. Sekine $H$, Komiyama $Y$, Hotta $H$, Yoshida K. Mobility characteristics and tactile sensitivity of ossointegrated fixture-supporting systems. In: van Steenberghe D, Albrektsson T, Branemark PI, Henry PJ, Holt R, Liden G, editors. Tissue Integration in Oral Maxillofacial Reconstruction. Amsterdam: Excerpta Medica; 1986. pp. 326-329.

15. Hobo S, Ichida E, Garcia LT. Osseointegration and Occlusal Rehabilitation. 1st ed. Tokyo: Ouintessence Pub Co; 1990.

16. Duyck J, Van Oosterwyck H, Vander Sloten J, De Cooman M, Puers R, Naert I. Magnitude and distribution of occlusal forces on oral implants supporting fixed prostheses: an in vivo study. Clin Oral Implants Res. 2000;11:465-475.

17. Zurdo J, Romão C, Wennström JL. Survival and complication rates of implantsupported fixed partial dentures with cantilevers: a systematic review. Clin Oral Implants Res. 2009;20(Suppl 4):59-66.

18. Vanlıoğlu B, Özkan Y, Kulak-Özkan Y, Oklüzyon IDR. Atatürk Üniv diş Hek Fak Derg. 2011;4:57-64.

19. Misch CE. Dental Implant Prosthetics. 2nd ed. St Louis: Mosby Elsevier; 2014.

20. Çalıkkocaoğlu S, Tedavisi Klasik DHP, Protezler T. Yayıncılık. İstanbul: Quintessence; 2010

21. Sahin S, Cehreli MC, Yalçin E. The influence of functional forces on the biomechanics of implant-supported prostheses--a review. I Dent. 2002;30:271-282.

22. Mericske-Stern RD, Taylor TD, Belser U. Management of the edentulous patient. Clin Oral Implants Res. 2000;11(Suppl 1):108-125.

23. Acar A, Inan Ö, Oklüzyon IDP. Cumhuriyet Dent J. 2001;4:52-56.

24. Yalçın S, Karabuda C, Özdemir T, Sandallı P. Implant Destekli Sabit Protezlerde Oklüzal Tablanın Kuvvet Dağılımı Açısından Değerlendirilmesi. Oral imp Der. 1995;2:29-33.

25. Lundgren D, Laurell L. Biomechanical aspects of fixed bridgework supported by natural teeth and endosseous implants. Periodontol. 2000;1994;4:23-40.

26. Bölümlü Protezler ÇS. Basımevi. 3rd ed. İstanbul: İstanbul Üniversitesi; 1996.

27. Rilo B, da Silva JL, Mora MJ, Santana U. Guidelines for occlusion strategy in implant-borne prostheses. A review. Int Dent J. 2008;58:139-145.

28. Curtis DA, Sharma A, Finzen FC, Kao RT. Occlusal considerations for implant restorations in the partially edentulous patient. J Calif Dent Assoc. 2000;28:771-779.

29. Wennerberg A, Jemt T. Complications in partially edentulous implant patients: a 5-year retrospective follow-up study of 133 patients supplied with unilateral maxillary prostheses. Clin Implant Dent Relat Res. 1999;1:49-56.

30. Ivanhoe JR, Vaught RD. Occlusion in the combination fixed removable prosthodontic patient. Dent Clin North Am. 1987;31:305-322.

31. Wismeijer D, van Waas MA, Kalk W. Factors to consider in selecting an occlusal concept for patients with implants in the edentulous mandible. J Prosthet Dent. 1995;74:380-384.

32. Weinberg LA. Reduction of implant loading with therapeutic biomechanics. Implant Dent. 1998;7:277-285.
33. Hobo S, Takayama H. Oral Rehabilitation Clinical Determination of Occlusion. 1st ed. Tokyo: Ouintessence Pub Co; 1998.

34. Davies SJ, Gray RJ, Young MP. Good occlusal practice in the provision of implant borne prostheses. Br Dent J. 2002;192:79-88.

35. Skalak R. Aspects of biomechanical considerations. In: Branemark PI, Zarb GA, Alberktsson T, editors. Tissue Integrate Prostheses: Osseointegration in Clinical Dentistry. 1st ed. Ouintessence Pub Co; 1985. p. 117-28.

36. Sullivan DY. Prosthetic considerations for the utilization of osseointegrated fixtures in the partially edentulous arch. Int J Oral Maxillofac Implants. 1986;1:39-45

37. Ericsson I, Lekholm U, Brånemark PI, Lindhe J, Glantz PO, Nyman S. A clinical evaluation of fixed-bridge restorations supported by the combination of teeth and osseointegrated titanium implants. J Clin Periodontol. 1986;13:307-312.

38. el Charkawi HG, Zekry KA, el Wakad MT. Stress analysis of different osseointegrated implants supporting a distal extension prosthesis. J Prosthet Dent. 1994;72:614-622.

39. Cohen SR, Orenstein JH. The use of attachments in combination implant and natural-tooth fixed partial dentures: a technical report. Int J Oral Maxillofac Implants. 1994;9:230-234.

40. Belser UC, Mericske-Stern R, Bernard JP, Taylor TD. Prosthetic management of the partially dentate patient with fixed implant restorations. Clin Oral Implants Res. 2000;11(Suppl 1):126-145.

41. Gunne J, Astrand P, Lindh T, Borg K, Olsson M. Tooth-implant and implant supported fixed partial dentures: a 10-year report. Int J Prosthodont. 1999;12:216-221.

42. Soto-Penaloza D, Zaragozí-Alonso R, Penarrocha-Diago M, Penarrocha-Diago M. The all-on-four treatment concept: systematic review. J Clin Exp Dent. 2017;9:e474-e488.

43. Maló P, Rangert B, Nobre M. 'All-on-Four' immediate-function concept with Branemark System implants for completely edentulous mandibles: a retrospective clinical study. Clin Implant Dent Relat Res. 2003;5(Suppl 1): 2-9.

44. Maló P, Friberg B, Polizzi G, Gualini F, Vighagen T, Rangert B. Immediate and early function of Branemark System implants placed in the esthetic zone: a 1-year prospective clinical multicenter study. Clin Implant Dent Relat Res. 2003;5(Suppl 1):37-46.

45. Maló P, Nobre Md, Lopes A. The rehabilitation of completely edentulous maxillae with different degrees of resorption with four or more immediately loaded implants: a 5-year retrospective study and a new classification. Eur J Oral Implantol. 2011;4:227-243.

46. Malo P, de Araújo Nobre M, Lopes A, Moss SM, Molina GJ. A longitudinal study of the survival of All-on-4 implants in the mandible with up to 10 years of follow-up. J Am Dent Assoc. 2011;142:310-320.

47. Tallarico M, Canullo L, Pisano M, Peñarrocha-Oltra D, Peñarrocha-Diago M, Meloni SM. An up to 7-year retrospective analysis of biologic and technical complication with the All-on-4 concept. J Oral Implantol. 2016;42:265-271.

48. Maló P, de Araújo Nobre M, Lopes A, Francischone C, Rigolizzo M. 'All-on-4' immediate-function concept for completely edentulous maxillae: a clinical report on the medium (3 years) and long-term (5 years) outcomes. Clin Implant Dent Relat Res. 2012;14(Suppl 1):e139-e150

49. Stoichkov B, Kirov D. Analysis of the causes of dental implant fracture: A retrospective clinical study. Quintessence Int. 2018;49:279-286.

50. Koyano K, Esaki D. Occlusion on oral implants: current clinical guidelines. J Oral Rehabil. 2015;42:153-161.

51. Penarrocha-Diago M, Penarrocha-Diago M, Zaragozí-Alonso R, Soto-Penaloza D, On Behalf Of The Ticare Consensus M. Consensus statements and clinical recommendations on treatment indications, surgical procedures, prosthetic 
protocols and complications following All-On-4 standard treatment. 9th Mozo-Grau Ticare Conference in Quintanilla, Spain. J Clin Exp Dent. 2017;9:e712-e715.

52. Agliardi E, Clericò M, Ciancio P, Massironi D. Immediate loading of full-arch fixed prostheses supported by axial and tilted implants for the treatment of edentulous atrophic mandibles. Quintessence Int. 2010;41:285-293.

53. Cavalli N, Barbaro B, Spasari D, Azzola F, Ciatti A, Francetti L. Tilted implants for full-arch rehabilitations in completely edentulous maxilla: a retrospective study. Int J Dent. 2012;2012:180379.

54. Di P, Lin Y, Li JH, et al. The All-on-Four implant therapy protocol in the management of edentulous Chinese patients. Int J Prosthodont. 2013;26:509516.
55. Ayna M, Gülses A, Açil Y. Comprehensive comparison of the 5-year results of all-on-4 mandibular implant systems with acrylic and ceramic suprastructures. J Oral Implantol. 2015;41:675-683.

56. Türker N, Büyükkaplan US, Sadowsky SJ, Özarslan MM. Finite element stress analysis of applied forces to implants and supporting tissues using the "all-on-four" concept with different occlusal schemes. J Prosthodont. 2019;28:185-194.

57. Türker N, Tercanlı Alkıș H, Sadowsky SJ, Büyükkaplan UȘ. Effects of occlusal scheme on All-on-Four abutments, screws and prostheses: A threedimensional finite element study. J Oral Implantol. 2020. doi:10.1563/aaidjoi-D-19-00334. 